\title{
Physiologic costs of reciprocal gait in FES assisted walking
}

\author{
P Winchester PhD PT, ${ }^{1}$ J J Carollo MS PE, ${ }^{1}$ R Habasevich MS PT ${ }^{2}$ \\ ${ }^{1}$ Mobility Research and Assessment Laboratory, University of Texas Southwestern \\ Medical Center, Dallas, Texas, USA; ${ }^{2}$ Sigmedics, Inc, Northfield, Illinois, USA
}

\begin{abstract}
This study reports the velocity and physiologic cost index (PCI) of ambulation using a functional electrical stimulation (FES) system for ambulation in paraplegic spinal cord injured subjects. Using established techniques, average velocity and heart rate (HR) were measured on five subjects trained with the Parastep ${ }^{\circledR}$ system. PCI was reported for the four subjects who achieved a steady state during ambulation with the Parastep ${ }^{\circledR}$ system. It was found that walking performance varied greatly between subjects, and was correlated to frequency of use of the system. Velocity of walking with the Parastep ${ }^{\circledR}$ system ranged from 4.6 to $24.3 \mathrm{~m} / \mathrm{min}$. In the four subjects where steady state was achieved, PCI ranged from 2.30 to 6.26 beats $/ \mathrm{m}$. The average walking speed and PCI were similar to the values reported using alternative mechanical or hybrid systems available to the spinal cord injured for restoration of upright locomotion.
\end{abstract}

Keywords: functional electrical stimulation (FES); paraplegic; gait; physiologic cost index (PCI).

\section{Introduction}

Although spinal cord injured individuals can move about their environments quite effectively using wheeled mobility devices, there are considerable psychological and physiological benefits to a program of assisted standing and walking. Practical efforts to restore upright, bipedal gait to paraplegics have most commonly relied on externally worn long leg orthoses. More recently, techniques employing electrical stimulation of paralyzed lower extremity muscles have been developed. ${ }^{1}$ These functional electrical stimulation (FES) systems employ portable, multichannel, electronic pulse generators connected to surface, percutaneous, or implanted electrodes of lower extremity muscles. When properly triggered by the subject, FES systems induce a series of artificial muscular contraction culminating in brief periods of standing and reciprocal gait. ${ }^{2}$

There are at least three mechanical systems currently in widespread clinical use for restoring upright mobility to the spinal cord injured. Bilateral knee, ankle, foot orthoses (KAFO) are typically used with a swing through gait pattern, where the individual is taught to swing both of the braced lower extremities forward by using trunk and upper extremities. Gait studies ${ }^{3-5}$ have reported high energy requirements and relatively slow walking speeds in spinal cord injured individuals using KAFOs and a swing through gait. Alternatively, two mechanical systems offer a reciprocal gait pattern: the Louisiana State University Reciprocating Gait Orthosis (RGO) ${ }^{6}$ and the Oswestry Parawalker Orthosis. ${ }^{7}$ Both the $\mathrm{RGO}^{8}$ and the Parawalker ${ }^{9}$ have been shown to increase the gait efficiency of paraplegics compared to walking with KAFOs and the swing through gait pattern.

In an attempt to further reduce the energy cost of walking in the spinal cord injury population, FES has been used in combination with mechanical orthoses in hybrid systems. One hybrid system uses FES to facilitate the swing phase of gait, while the RGO provides rigid external support for stance stability. ${ }^{10}$ Studies have demonstrated that FES slightly reduces the energy costs associated with paraplegic ambulation in the RGO. ${ }^{8}$ In another hybrid system, FES has been used to stimulate the gluteal muscles during the stance phase of gait in patients using the Parawalker. ${ }^{11}$ One 
report demonstrated that the use of FES resulted in a small reduction in energy costs compared to walking with the Parawalker orthosis without stimulation. ${ }^{12}$ The increased complexity associated with these hybrid systems may not warrant the slight improvement in energy cost.

Although there is a considerable body of knowledge associated with FES, only two brief reports have considered the energy cost and walking speed of subjects using a pure FES gait assist device. ${ }^{13,14}$ Both of these studies reported on a limited sample size $(n=2)$ with limited time training with the FES gait assist system. This scarcity of research is due in part to the limited and isolated use of these systems in the clinical setting. ${ }^{15}$ In an effort to bridge the gap between research and widespread technology utilization, Sigmedics, Inc (Northfield, IL) introduced a commercially available FES system in 1990. The Parastep ${ }^{\circledR}$ system is similar in design to the Ljubljana FES walking system ${ }^{16}$ first described in the early 1970s. Sigmedics, Inc initiated clinical trials in 1990 and recently, the Orthpaedic and Devices Advisory Panel of the Food and Drug Administration recommended approval of the Parastep ${ }^{\circledR}$ gait assist system. ${ }^{17}$ The objective of this study was to determine the overall gait performance of paraplegic subjects who had been using the Parastep ${ }^{\circledR}$ system for a minimum of 1 year.

Any outcome measure of overall gait performance should describe how well the subject performs the task of walking. Energy expenditure is traditionally determined through the measurement of oxygen consumption; however, these methods require a mouthpiece, nose clip and headgear that may alter the patient's customary gait pattern. The Physiologic Cost Index (PCI) is an index of gait performance, introduced by MacGregor in 1979. ${ }^{18} \mathrm{PCI}$ is obtained by combining measurements of speed and heart rate (HR) and is determined as follows:

$$
\operatorname{PCI}(\text { beats } / \mathrm{m})=\frac{\mathrm{HR}_{w}-\mathrm{HR}_{r}}{v}
$$

where, $\mathrm{HR}_{w}$ (beats/min) is the $\mathrm{HR}$ during steady state walking,

$\mathrm{HR}_{r}$ (beats/min) is resting $\mathrm{HR}$, and $v$ is the average speed in $\mathrm{m} / \mathrm{min}$.

PCI has been shown to be proportional to traditional measures of oxygen uptake and a useful indicator of energy costs in disabled individuals. ${ }^{19}$ It has also been used as an indicator of gait efficiency in spinal cord injured individuals who utilize different mechanical $^{20,21}$ and hybrid orthoses ${ }^{22,23}$ for reciprocal ambulation.

This study reports the PCI and average walking velocity of FES assisted reciprocal gait in a group of trained Parastep ${ }^{\circledR}$ users, all of whom had received identical systems and training prior to laboratory testing.

\section{Methods}

\section{Subjects}

Five subjects fully trained in the use of the Parastep ${ }^{\circledR}$ system volunteered for this study. Subject profiles are summarized in Table I. All subjects had complete injuries at the thoracic level between T4 and T12 secondary to trauma. Subjects with injuries above T3 were excluded since the sympathetic contribution to the cardiac plexus may not be intact in spinal cord injuries above the level of T4. ${ }^{24}$ All subjects were independent

Table I Subject information

\begin{tabular}{lcccccccc}
\hline Subject & $\begin{array}{c}\text { Age } \\
(\mathrm{yrs})\end{array}$ & Sex & $\begin{array}{c}\text { Height } \\
(\mathrm{m})\end{array}$ & $\begin{array}{c}\text { Weight } \\
(\mathrm{kg})\end{array}$ & $\begin{array}{c}\text { Level } \\
\text { of } \\
\text { injury }\end{array}$ & $\begin{array}{c}\text { Time since } \\
\text { injury } \\
\text { (months) }\end{array}$ & $\begin{array}{c}\text { Monthly } \\
\text { use } \\
\text { (hrs) }\end{array}$ & $\begin{array}{c}\text { Time of } \\
\text { training } \\
\text { (months) }\end{array}$ \\
\hline 1 & 20 & Male & 1.80 & 59.09 & T12 & 26 & 15 & 12 \\
2 & 20 & Male & 1.83 & 61.36 & T6 & 21 & 7.5 & 12 \\
3 & 26 & Male & 1.70 & 62.27 & T7 & 84 & 30 & 18 \\
4 & 28 & Female & 1.65 & 47.73 & T4 & 39 & 4 & 24 \\
5 & 37 & Male & 1.73 & 72.73 & T10 & 23 & 7.5 & 18 \\
\hline
\end{tabular}


in Parastep ${ }^{\circledR}$ use and the average time using the system was $16.8 \pm 5.0$ months. Each of the subjects had received 32 sessions of physical therapy during their initial training with the system, but none of the subjects were involved in any formalized clinical program at the time of this study. The frequency of use varied widely among the subjects, from daily to once every 2 weeks.

\section{FES gait assist system}

The Parastep ${ }^{\circledR}$ system uses a portable, six channel, microprocessor controlled muscle stimulator, paired surface electrodes placed over antigravity muscles at the hip (gluteus maximus) and knee (quadriceps) bilaterally, and on the lateral upper tibial region of both lower legs. These upper tibial electrodes were used to elicit a flexion withdrawal response via intact spinal interneurons, that produced muscular contractions of the hip and knee flexors of a magnitude sufficient to initiate a step on the stimulated side. The subject initiated the simulation sequence for taking a single step when the user pressed a button mounted on the handle of a specially instrumented rolling walker. From there, a preset sequence of bilateral muscle stimulation followed to produce a step on the triggered side, and an extended limb on the contralateral side. This continued until the step was completed and the user pressed another button to initiate an identical stepping sequence on the contralateral side.

\section{Instrumentation}

Video documentation of all subject testing was recorded with a two camera system that provided simultaneous lateral and anteriorposterior views. Photocells mounted at either end of a measured walkway provided an elapsed time measurement for each pass completed by the subject. Simultaneous foot/floor contact events were collected using thin, flexible footswitches attached to the heel, fifth metatarsal, first metatarsal and first toe of both feet. The footswitches were connected to a special purpose fiber optic transmitter for data transmission to a computerized recording system. These data allowed automatic calculation of average velocity and cadence for each gait pass recorded from the subjects.

HR was monitored continuously using a wireless electrocardiogram (ECG) telemetry system (Transkinetics, Inc). ECG electrodes were place on the left midclavicular line and the midsternal line. The transmitter was attached to the electrodes and taped securely to the trunk of the subject. HR was collected during quiet sitting for $5 \mathrm{~min}$, for $30 \mathrm{~s}$ after the subject was standing with FES assistance, and during each FES walking trial.

\section{Experimental procedure}

Each subject was instructed to walk at a self-selected velocity down a $5 \mathrm{~m}$ gait lane while being videotaped from the front and side. Elapsed time, cadence, and average velocity were collected over the middle $2.67 \mathrm{~m}$ of the walkway. The subjects were instructed to turn at the end of the gait lane and complete as many passes as possible. During the walking trials, ECG was recorded continuously, but HR was calculated only after the completion of each pass. This enabled all gait performance variables to be accumlated on a pass by pass basis. The PCI was calculated for each pass and the mean PCI was determined for each subject after reaching steady state.

\section{Results}

The subject was assumed to be at a steady state when his or her HR and PCI maintained a constant level regardless of continued effort during the walking trials. One individual's (subject 5) PCI and HR for each pass of ambulation is illustrated in Figure 1. A relative steady state was seen to result after three passes. In the first three passes, both HR and PCI continued to increase until the fourth pass when the subject's HR and PCI stabilized. This pattern was observed in all of the subjects except for subject 4 who was only able to ambulate $11 \mathrm{~m}$ before tiring. Due to the limited distance that this subject ambulated, a steady state was never achieved so PCI was not reported.

The data for average velocity, cadence, 


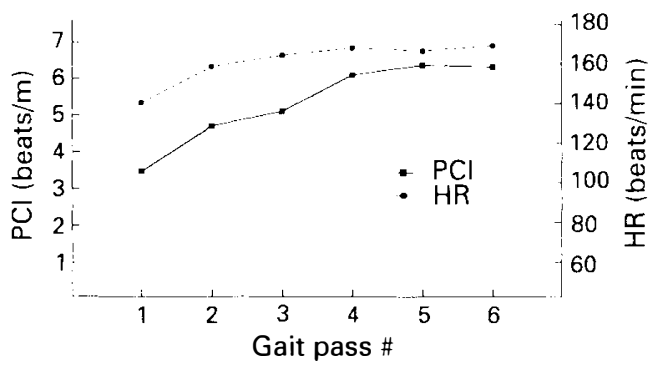

Figure 1 Subject 5's physiologic cost index (PCI) and heart rate (HR) for each gait pass showing steady state achieved after pass \#4. Values of PCI $(\boldsymbol{\square})$ are plotted with a solid line and HR values $(\Theta)$ are plotted with a broken line.

PCI, and total distance ambulated are summarized for each of the subjects in Table II. The values represent the mean $\pm S D$ for velocity, cadence, and PCI for the passes completed after the subject achieved a steady state during walking. There was great variability in the subjects' gait performance, as evidenced by the wide range in average velocity, cadence, and PCI. PCI was found to vary between subjects, ranging from 2.30 to 6.26 beats $/ \mathrm{m}$. PCI was highly correlated with the averge amount of time during which each subject used the system in a month $(r=-0.996)$.

\section{Discussion}

A wide range of walking performance was observed in this study. Average walking velocity ranged from a minimum of
$4.6 \mathrm{~m} / \mathrm{min}$ to a maximum of $24.3 \mathrm{~m} / \mathrm{min}$. In the four subjects that achieved steady state, PCI varied from 2.30 to 6.26 beats $/ \mathrm{m}$. In comparison, average velocity during free cadence walking in age matched control subjects is 88.1 and $81.2 \mathrm{~m} / \mathrm{min}$ for males and females, respectively. ${ }^{25} \mathrm{PCI}$ averages 0.21 beats $/ \mathrm{m}$ in normal subjects during walking at self selected speeds. ${ }^{26}$ These results demonstrate that Parastep $^{\circledR}$ users perform at significantly different levels when using the system, and that in this study, even the best users are slower and less energy efficient than normal walkers.

These results are not surprising when one compares the mechanics of normal gait to the locomotion pattern adopted by the typical Parastep ${ }^{\circledR}$ user. The principle goal of purposeful locomotion is to propel the body forward and the most efficient way to accomplish this is to use a reciprocal pattern of locomotion. Although the Parastep ${ }^{\circledR}$ system produces a reciprocal pattern of locomotion, the mechanics are quite different from normal gait. Normally, weight transfer is smooth and rhythmic, maintaining forward inertia while simultaneously protecting the body from tumbling to the floor. Locomotion with the Parastep ${ }^{\circledR}$ system is considerably less fluid, due in large part to the relatively inefficient and uncoordinated movement that is the necessary consequence of electrically induced muscle contraction. Videotape review of the walking trials demonstrated two characteristics common to all subjects; excessive upper extremity and trunk motion and absence of a smooth continuous transition from the st-

Table II Summary of average velocity, cadence, and PCI for each subject and the total distance ambulated

\begin{tabular}{lrccc}
\hline Subject & $\begin{array}{c}\text { Velocity } \\
(\mathrm{m} / \mathrm{min})\end{array}$ & $\begin{array}{c}\text { Cadence } \\
(\text { steps/min) }\end{array}$ & $\begin{array}{c}\text { PCI } \\
\text { (beats/m) }\end{array}$ & $\begin{array}{c}\text { Distance } \\
\text { walked (m) }\end{array}$ \\
\hline 1 & $9.35 \pm 0.07$ & $32.8 \pm 0.3$ & $4.80 \pm 0.95$ & 32.00 \\
2 & $12.25 \pm 1.49$ & $25.1 \pm 2.3$ & $5.87 \pm 1.00$ & 30.79 \\
3 & $24.28 \pm 2.66$ & $45.0 \pm 5.8$ & $2.30 \pm 0.23$ & 61.87 \\
4 & $4.60 \pm 1.37$ & $14.1 \pm 0.7$ & $\mathrm{a}$ & 10.97 \\
5 & $12.01 \pm 0.38$ & $30.3 \pm 2.0$ & $6.26 \pm 0.14$ & 29.43 \\
\hline
\end{tabular}

Values are mean $\pm \mathrm{SD}$.

aPCI was not reported for subject 4 since a steady state was not achieved in the short distance ambulated. 
ance to the swing phase. These observations offer a reasonable explanation for the slower velocities and increased PCI found in this study, and suggest that stimulation patterns producing more fluid motion may improve the walking performance of subjects using the Parastep ${ }^{\circledR}$ system.

An interesting result of this study is that PCI and average velocity were not related to level of lesion, age, body morphometrics, or time of Parastep ${ }^{\circledR}$ use. Instead, the physiologic demand of walking was correlated to the subject's ongoing frequency of Parastep ${ }^{\circledR}$ use. Subject 3 had the smallest physiologic demand, the fastest average velocity, and used the system multiple times each day; more often than any other subject. Conversely, subject 4 was only able to walk at a velocity of $4.6 \mathrm{~m} / \mathrm{min}$ for $11 \mathrm{~m}$ before fatiguing. This subject practiced walking once every 2 weeks, despite having used the system the longest (24 months). These results suggest that efficient use of the Parastep ${ }^{\circledR}$ system cannot be realized unless the user is dedicated enough to use the system on a regular basis. The addition of mandatory, ongoing, clinical follow up as part of system delivery may provide sufficient motivation for Parastep ${ }^{\circledR}$ users to continue to use their systems after the initial training period.

It is important to note that the correlation between PCI and frequency of use is based on a limited number of users. Furthermore, subject selection may have influenced these results. The subjects were selected for this study because they were experienced users of the Parastep ${ }^{\circledR}$ system and had the same 32 sessions of training. The selection criteria for acceptance into the Parastep ${ }^{\circledR}$ clinical program and the standardized training program may have masked other factors that may be related to the physiologic demand of walking with this system. Clinkingbeard and coworkers ${ }^{3}$ reported that the level of neurologic lesion and time of training correlated with the energy cost of ambulation in bilateral KAFOs; however Nene \& Patrick ${ }^{9}$ found no correlation between level of lesion or duration of use and energy consumption with the Parawalker. These studies did not report the frequency of use in their subjects.

Two other reports were found to report energy expenditure of walking with a pure FES system. ${ }^{13,14}$ Isakov and coworkers ${ }^{14}$ trained two paraplegic subjects to stand and walk using a system similar to the Parastep $^{\circledR}$ system and reported an average walking velocity of $5.8 \mathrm{~m} / \mathrm{min}$ and a $423 \%$ increase in oxygen uptake during ambulation. Using their HR and velocity data, we estimated a PCI of approximately 13.4 and 15.0 beats $/ \mathrm{m}$, respectively, for their two subjects. These values are greater than the values we reported in this study. This is likely due to the limited time of training that their subjects had compared to the subjects in our study.

Miller and coworkers ${ }^{13}$ evaluated the energy costs of walking with the VA-Case Western Reserve University system in two paraplegic subjects. This system employs 48 channels of percutaneous stimulation to lower extremity muscles for activation during swing and stance. In this study, Miller and colleagues ${ }^{13}$ controlled for velocity and measured oxygen consumption and reported that their subjects used three and a half times the oxygen consumption used by normal walkers. Unfortunately, PCI could not be calculated since velocity was controlled and HR was not reported.

The merits of the Parastep ${ }^{\circledR}$ system can be evaluated in a number of ways; however, measures of overall gait performance such as PCI are particularly useful since they permit comparison to other mechanical systems for walking in paraplegic subjects. Other investigators have reported PCI as an indicator of energy expenditure when walking using mechanical bracing for reciprocal gait in adult spinal cord injured individuals. ${ }^{20-23}$

Bowker and colleagues ${ }^{20}$ reported an average PCI of $6.71 \pm 4.02$ beats $/ \mathrm{m}$ in a group of seven adult traumatic paraplegic subjects using the RGO. This value is higher (less efficient) than the mean PCI of the four subjects in this study $(4.81 \pm 1.78$ beats $/ \mathrm{m})$. As with this study, Bowker and coworkers ${ }^{20}$ reported a great range of PCI values in their sample group: $2.37-14.33$ beats $/ \mathrm{m}$. Bowker and colleagues ${ }^{20}$ measured PCI when one of their subjects, a 24 year old male paraplegic patient, ambulated with the RGO and the hip guidance orthosis. PCI was slightly 
lowered with the subject ambulating with the hip guidance orthosis compared to the RGO: 5.33 and 6.01 beats/m, respectively.

Isakov and coworkers ${ }^{23}$ reported the results of a single subject's PCI during ambulation with an RGO and then when FES was used in combination with the RGO. PCI values fell from 2.55 to 1.54 beats $/ \mathrm{m}$ when FES was used to augment the RGO. These values are significantly lower than the mean value of PCI reported for the four subjects in this study; however, the most efficient walker in this study (subject 3) had a PCI value comparable to the subject studied by Isakov and coworkers. ${ }^{23}$ Their subject had been using the RGO for 2 years and practiced for 2 hours at least four times a week. This data supports our conclusion that frequency of system use is an important factor in increasing energy efficiency of walking.

We recently reported PCI values in five paraplegic subjects who had been trained to ambulate with an RGO and a modified isocentric RGO (21). PCI values averaged $3.6 \pm 0.7$ with the RGO and $2.6 \pm$ 0.5 beats $/ \mathrm{m}$ with the modified isocentric RGO. As with Isakov and coworkers' study, ${ }^{23}$ these values are lower than those reported in this study. The subjects in this earlier study ${ }^{21}$ walked for an average of $2 \mathrm{~h}$ two to three times a week before being tested. This aggressive training was more than that performed by most of the subjects in this study.

\section{Conclusions}

Just as with other upright mobility devices for the spinal cord injured, the Parastep ${ }^{\circledR}$ system is slower and less energy efficient than normal walking. However, this system was shown to provide comparable performance to the other orthotic options currently available to the spinal cord injured population, without the need for the bulky external braces common to hybrid systems. Regular use of the Parastep ${ }^{\circledR}$ system after initial training can provide upright mobility at a reasonable walking velocity and energy cost. Whether the effort necessary to achieve this level of performance is justified depends on the value one places on upright locomotion, and can only be determined on an individual basis.

\section{Acknowledgements}

The authors would like to thank Claudia Castaño, Sudha Thimmaraju, and Judy Hembree for their assistance during data collection. The authors would also like to thank Dr George Wharton and Dallas Rehabilitation Institution for their continued support of the Mobility Research and Assessment Laboratory.

\section{References}

1 Jaeger RJ (1992) Lower extremity applications of functional neuromuscular stimulation. Assist Technol 4: 19-30.

2 Campbell JM, Meadows PM (1992) Therapeutic FES: from rehabilitation to neural prosthetics. Assist Technol 4: 4-18.

3 Clinkingbeard JR, Gesten JW, Hoehn D (1964) Energy cost of ambulation in traumatic paraplegic. Am J Phys Med 43: 157-165.

4 Chantraine A, Crielaared JM, Onkelinx A, Pirnay F (1984) Energy expenditure of ambulation in paraplegics: effects of long term use of bracing. Paraplegia 22: 173-181.

5 Waters RL, Yakura JS, Adkins R, Barnes G (1989) Determinants of gait performance following spinal cord injury. Arch Phys Med Rehabil 70: 811-818.

6 Douglas R, Larson PF, D'Ambrosia R, McCall RE (1983) The LSU reciprocating gait orthosis. Orthopedics 6: 834-838.

7 Stallard J, Major RE, Poiner R, Farmer IR, Jones N (1986) Engineering design considerations of the ORLAU ParaWalker and FES hybrid system. Eng Med 15: 123-129.

8 Hirokawa S, Grimm M, Le T, Solomonow M, Baratta RV, Shoji H, D'Ambrosia RD (1990) Energy comsumption in paraplegic ambulation using the reciprocating gait orthosis and electrical stimulation of the thigh muscles. Arch Phys Med Rehabil 71: 687-694.

9 Nene AV, Patrick JH (1989) Energy cost of paraplegic locomotion with the ORLAU ParaWalker. Paraplegia 27: 5-18.

10 Solomonow M, Baratta R, Hirokawa S et al (1989) The RGO generation II muscle stimulation powered orthosis as a practical walking system for thoracic paraplegics. Orthopedics 12: 1309-1315. 
11 McClelland M, Andrews BJ, Patrick JH et al (1987) Augmentation of the Oswestry Parawalker orthosis by means of surface electrical stimulation: gait analysis of three patients. Paraplegia 35: 32-38.

12 Nene AV, Patrick JH (1990) Energy cost of paraplegic locomotion using the ParaWalker-electrical stimulation 'hybrid' orthosis. Arch Phys Med Rehabil 71: 116-120.

13 Miller P, Kobetic R, Lew R (1990) Energy costs of walking and standing using functional electrical stimulation. Proc 13th Association for the Advancement of Rehabilitation and Assistive Technologies Ann Conf, Washington: $155-156$.

14 Isakov E., Mizrahi J, Najenson T (1986) Biomechanical and physiological evaluation of FES-activated paraplegic patients. J Rehabil Res Dev 23: 9-19.

15 Marsolais EB, Kobetic R, Chizeck HJ, Jacobs JL (1991) Orthoses and electrical stimulation for walking in complete paraplegia. J Neurol Rehabil 5: 13-22.

16 Kralj A, Bajd T (1989) Functional Electrical Stimulation: Standing and Walking after Spinal Cord Injury. CRC Press, Boca Raton, FL.

17 Medical Devices, Diagnostics \& Instrumentation Reports-'The Gray Sheet' (1993), Vol 18. Chevy Chase, MD: $1-3$.

18 MacGregor J (1979) The objective measurement of physical performance with long-term ambulatory physiological surveillance equipment (LAPSE). Proc 3rd Int Symp on Ambulatory Monitoring, London: 29-39.

19 Rose J, Gamble JG, Medeiros JM et al (1989) Energy cost of walking in normal children and in those with cerebral palsy: comparison of heart rate and oxygen uptake. J Pediatr Orthop 9: 276-279.

20 Bowker P, Messenger N, Ogilvie C, Rowley DI (1992) Energetics of paraplegic walking. J Biomed Eng 14: 344-350.

21 Winchester PK, Carollo JJ, Parekh RN et al (1993) A comparison of paraplegic gait performance using two types of reciprocating gait orthoses. Pros 17: 101-106.

22 Stallard J, Rose GK (1980) Clinical decision making with the aid of ambulatory monitoring of heart rate. Prosthet Orthot Int 4: 91-96.

23 Isakov E, Douglas R, Berns P (1992) Ambulation using the reciprocating gait orthosis and functional electrical stimulation. Paraplegia 30: 239-245.

24 Bar-On ZH, Nene AV (1990) Relationship between heart rate and oxygen uptake in thoracic level paraplegics. Paraplegia 28: 87-95.

25 Perry J (1992) Stride Analysis. In: Gait Analysis Normal and Pathological Function. Slack Inc, Thorofare, NJ.

26 Hamzeh M, Bowker P, Rowley D (1988) Below-knee cast design and the energy cost of ambulation. Clin Biomech 3: 74-78. 